Abstracta Iranica Abstracta Iranica

Revue bibliographique pour le domaine irano-aryen

Volume 34-35-36 | 2017

Comptes rendus des publications de 2011-2013

\title{
Pierfrancesco Callieri, Alireza Askari Chaverdi. Media, Khuzestan and Fars between the end of the the Achaemenids and the rise of the Sasanians
}

Rémy Boucharlat

\section{OpenEdition}

1 Journals

Édition électronique

URL : http://journals.openedition.org/abstractairanica/42357

DOI : 10.4000/abstractairanica.42357

ISSN : 1961-960X

Éditeur :

CNRS (UMR 7528 Mondes iraniens et indiens), Éditions de l'IFRI

Référence électronique

Rémy Boucharlat, « Pierfrancesco Callieri, Alireza Askari Chaverdi. Media, Khuzestan and Fars between the end of the the Achaemenids and the rise of the Sasanians », Abstracta Iranica [En ligne], Volume 34-35-36 | 2017, document 63, mis en ligne le 30 juillet 2017, consulté le 29 septembre 2020. URL: http://journals.openedition.org/abstractairanica/42357 ; DOI : https://doi.org/10.4000/

abstractairanica. 42357

Ce document a été généré automatiquement le 29 septembre 2020.

Tous droits réservés 


\title{
Pierfrancesco Callieri, Alireza
} Askari Chaverdi. Media, Khuzestan and Fars between the end of the the Achaemenids and the rise of the Sasanians

\author{
Rémy Boucharlat
}

\section{RÉFÉRENCE}

Pierfrancesco Callieri, Alireza Askari Chaverdi. « Media, Khuzestan and Fars between the end of the the Achaemenids and the rise of the Sasanians ", in: D.T. Potts, éd., The Oxford Handbook of Ancient Iran. New York, Oxford University Press, 2013, p. 690-717.

Ces cinq siècles sont souvent considérés comme une période de "dark ages ", en particulier dans le Fars, car la documentation non seulement pauvre mais difficile à manier. En Médie, si les copies de la grande inscription d'Antiochos III sont importantes car elles informent dur l'administration et les cultes grecs du début du $\mathrm{II}^{\mathrm{e}} \mathrm{s}$. av. n.è., les imposants vestiges d'Ecbatane n'ont été que récemment datés de la seconde partie de la période parthe, tandis que ceux de Kangavar sont maintenant attribués à la période sassanide et non plus séleucide. Dans le Khuzestan, Suse reste le site majeur parce qu'il a été longuement fouillé, mais fort mal pendant des décennies. Toutefois les derniers travaux du XXe s. et des études ponctuelles, comme celle de l'urbanisme, des pratiques funéraires et des figurines précisent un peu le tableau. De même, les études renouvelées sur Masjid-i Solaiman et Bard-e Neshandeh permettent de dater les temples construits et la sculpture qu'ils ont livrée de l'époque parthe et non pas séleucide. Dans le Fars, les documents sont plus dispersés. Quelques faits ressortent : la continuité dans l'occupation d'une partie de la terrasse de Persépolis après Alexandre ; la continuité de l'occupation dans certaines régions, comme celle des Mamassani 
(Nurabad), phénomène qui n'est seulement un biais de l'imprécision des résultats de la recherche, comme dans la région de Persépolis où la distinction entre la poterie des époques achéménide et post-achéménide commence tout juste à émerger ; la mise en évidence de documents de la fin de l'époque considérée ( $\mathrm{I}^{\mathrm{er}}-\mathrm{III}^{\mathrm{e}} \mathrm{s}$. de n.è.) par comparaison avec des œuvres romaines.

\section{AUTEURS}

\section{RÉMY BOUCHARLAT}

UMR 5133 CNRS-Université de Lyon 